Research Article Animal Genetics

\title{
Fire ants: What do rural and urban areas show us about occurrence, diversity, and ancestral state reconstruction?
}

\author{
Manuela de O. Ramalho' (D), Leonardo Menino², Rodrigo F. Souza ${ }^{2}$ (D), Débora Y. Kayano² (D), \\ Juliana M. C. Alves ${ }^{2}$ (1), Ricardo Harakava ${ }^{3}$ (D), Victor H. Nagatani ${ }^{2}$ (D), Otávio G. M. Silva ${ }^{4}$ (i), \\ Odair C. Bueno 5 (D) and Maria S. C. Morini ${ }^{2}$ (1) \\ ${ }^{I}$ Cornell University, Department of Entomology, Ithaca, USA. \\ ${ }^{2}$ Universidade de Mogi das Cruzes, Mogi das Cruzes, SP, Brazil. \\ ${ }^{3}$ Secretaria de Agricultura e Abastecimento, Instituto Biológico, Laboratório de Bioquímica Fitopatológica, \\ São Paulo, SP, Brazil. \\ ${ }^{4}$ Museu Paraense Emilio Goeldi, Coordenação de Ciências da Terra e Ecologia, Belém, PA, Brazil. \\ ${ }^{5}$ Universidade Estadual Paulista (UNESP), Instituto de Biociências, Departamento de Biologia Geral \\ e Aplicada, Rio Claro, SP, Brazil.
}

\begin{abstract}
In South America, Solenopsis saevissima and S. invicta are the most common fire ants. Nests are founded in areas under anthropic interference like urban or rural areas, but S. invicta is found preferentially in those with the greatest anthropic interference. However, we do not know the rates at which they exist in anthropized areas next to high density of native vegetation. Areas with 60 to $90 \%$ of native Atlantic Forest were selected to verify the occurrence of both species in rural and urban areas. We investigated the molecular diversity and applied the reconstruction of the ancestral state analysis for each species. A total of 186 nests were analyzed and we found that the two species had the same proportion in the urban area. However, S. saevissima had a higher rate of prevalence in the rural area, in addition to having a greater number of haplotypes and ancestry associated with this type of habitat for the region. $S$. invicta had the same number of haplotypes in both rural and urban regions, and less haplotypic diversity. We conclude that $S$. saevissima is a species typically associated with rural areas and S. invicta, although present, is not dominant in urban areas.
\end{abstract}

Keywords: Biodiversity, haplotype diversity, DNA barcoding, mtDNA.

Received: June 10, 2021; Accepted: January 18, 2022.

\section{Introduction}

Solenopsis (Myrmicinae: Solenopsidini) has 196 species, in addition to 22 subspecies (Bolton 2021), with a widespread distribution. In the Neotropical region, there are a total of 101 species; 43 of these species are found in Brazil and 25 of them are found in the state of São Paulo (AntWeb, 2021). Specieslevel identification is difficult (Trager, 1991; Pacheco et al., 2013), especially in the Neotropical Region which has high diversity (Pitts et al., 2018). There are species characterized by workers of small size and, monomorphic that form small colonies and can exhibit a lestobiotic lifestyle, known as thief ants (Pacheco et al., 2013). Others are known as fire ants, which include species with larger workers, polymorphic and populous colonies (Trager, 1991).

Fire ants are found in South America (Pitts et al., 2018), where they exhibit omnivorous, opportunistic and aggressive behavior (Pitts, McHugh and Ross, 2005). In addition, they display variation in social structure (Tschinkel, 2006) and in larvae morphology (Pitts et al., 2018). In this group, we still

Send correspondence to Manuela de O. Ramalho. Cornell University, Department of Entomology, 129 Garden Avenue, 14853, Ithaca, NY, USA. E-mail: manu.ramalho@ cornell.edu. find social parasitic species (e.g., S. daguerrei and S. hostilis) (Pitts et al., 2018). The nests are founded, especially, in open and sunny areas, such as pastures (Pacheco and Vasconcelos, 2007; Rabello et al., 2018), crops (Lunz et al., 2009) and urban (Ulloa-Chacon, 2003; Pacheco and Vasconcelos, 2007; Zeringóta et al., 2014). Fire ants cause damage to biodiversity (Dejean et al., 2015), crops (Chan and Guenard, 2020) and also health problems for people who are allergic to the venom (Haddad Junior and Larsson, 2015). Farmers estimate losses of $10 \%$ to $80 \%$ in production due to fire ants, especially related to $S$. invicta (Chan and Guenard, 2020). In addition to damage to agriculture, the USA and China report impacts of S. invicta on civil construction and public health sectors (Banks et al., 1990; Wang et al., 2019). In Brazil, there is little knowledge about the impact caused by fire ants on agriculture, however there are records of large infestations associated with health problems, mainly due to allergies (Fernandes et al., 2016).

In South America, S. saevissima and S. invicta are the most common fire ants (Fowler et al., 1990; Tschinkel, 2006; Pitts et al., 2018). S. saevissima is distributed throughout the Brazilian coast, including the Amazon region. S. invicta is largely in the Pantanal region, close to the Paraguay River. This area is composed of savannas and seasonally inundated wetlands (Pitts et al., 2018). Both species are found 
in rural (e.g., crops) and urban areas (Fowler, Bernardi and di Romagnano, 1990; Dejean et al., 2015). However, the area of occurrence of $S$. invicta is expanding to exclusive sites of S. saevissima (see Pitts et al., 2005, Martins et al., 2014; Fox et al., 2012; Souza et al., 2014).

Morphologically the nests are similar both on the outside (Penick and Tschinkel, 2008; Zeringóta et al., 2014) and on the inside, where they consist of labyrinths and galleries about 1 to $1.5 \mathrm{~m}$ deep. These galleries are used for protection, movement of workers in search for food, storage of resources and garbage disposal (Penick and Tschinkel, 2008; Wilder et al., 2013). Both species are aggressive (Roux et al., 2013; Lai et al., 2015) and, although they depend on practically the same resources, foraging behavior occurs in different periods. S. saevissima is more nocturnal (Orivel and Dejean, 2002; Dejean et al., 2015) and S. invicta has diurnal habits (Porter and Tschinkel, 1987).

The use of land for different purposes alters the landscape structure, as e.g., by loss of biotic and abiotic resources. That can affect ant communities (Crist, 2009), benefiting some species at the expense of others (Schoereder et al., 2004). The Atlantic Forest biome has been hurt by fragmentation (Joly et al., 2014), which is mostly related to anthropogenic activities (Tabarelli et al., 2005; Ribeiro et al., 2009). Therefore, we seek in this study to investigate the occurrence of $S$. saevissima and $S$. invicta in rural and urban areas interspersed with fragments of the Atlantic Forest. Even though S. invicta is associated with more ecologically disturbed environments, especially related to human-associated habitats (King and Tschinkel, 2008; Bertelsmeier et al., 2015), we expect to find fewer nests in urban areas when compared to $S$. saevissima because the region we chose to study has many fragments of conserved Atlantic Forest (Sartorello, 2018). This can be a barrier to the dispersion of the species. In addition, we seek to identify the molecular diversity of S. saevissima and S. invicta and apply the reconstruction of the ancestral state analysis for each species in order to fill the knowledge gap regarding the origin of the dispersion (urban or rural) for each species.

\section{Material and Methods}

\section{Collection areas}

The collections were carried out in areas belonging to the Atlantic Domain of the Southeast region of Brazil (Fiaschi and Pirani, 2009; Colombo and Joly, 2010). The collections were carried out between September 2015 and March 2017, on sunny days and with a minimum rain interval of one week. In the urban and rural areas $(n=21$ locations in each area; Table S1) we carry out a linear transect (total $=12 \mathrm{~km}^{2}$ ), where nests were collected every 20 meters. Classification of rural and urban areas is in accordance with the Brazilian Institute of Geography and Statistics (IBGE, 2020). Thus, we considered rural areas as places destined for agricultural or livestock activities; and urban area where there is the presence of city infrastructure (e.g., pavement, rainwater channeling, water supply, sanitary sewer system and public lighting network).

Entire nests were sampled from the surface to a depth of $5 \mathrm{~cm}$, using a gardening shovel (see geographical coordinates in Table S1). The collected content was placed in a plastic pot
(5 L) previously coated with teflon. In the laboratory, the ants were separated from the soil using the drip technique (Bueno, 2017). To standardize this collection, the entire procedure was performed by the same person. Then the ants were placed in $95 \%$ ethanol and stored in a $-20{ }^{\circ} \mathrm{C}$ freezer at the Alto Tietê Myrmecology Laboratory of University of Mogi das Cruzes, São Paulo, Brazil. Field capture and collections were authorized by the Chico Mendes Institute for Biodiversity Conservation, Brazil (ICMBio / SISBIO permits n. 66500). For the following analyses, 186 nests were selected (rural area: 93; urban area: 93; Table $\mathrm{S} 1$ ).

\section{Species identification}

Morphological identification was performed using three major workers from each nest (see Pitts et al., 2018). For better visualization of the morphological characters, Scanning Electron Microscopy (SEM) images were performed, specifically from the frontal view of the head, lateral view of the mesosome, and view of the posterior portion of the postpetiole of the specimens. High-resolution images in front view were taken in the multi-focus image overlay system, with the AutoMontage $\AA$ program and a Leica M205C $\AA$ stereomicroscope coupled to a Leica DFC $295 \AA$ camera.

We performed molecular identification in all nests (Figure $\mathrm{S} 1)$. The specimens $(\mathrm{n}=3$ for each nest) were also identified using the DNA Barcode technique, which uses a stretch of mtDNA - COI and compares with sequences deposited in a database, such as GenBank (https://www.ncbi. nlm.nih.gov/genbank/) and BOLDSYSTEM (http://www. boldsystems.org/) (Hebert et al., 2003; Ratnasingham and Hebert, 2007). The total DNA of each organism was extracted separately, following the protocol adapted from Martins et al. (2014). The total DNA of each specimen was used to generate an approximately $920 \mathrm{bp}$ fragment of Cytochrome Oxidase I - COI, using the CIJ and DDS primers described by Ahrens et al. (2005). The sequencing reactions were performed with the reagent BigDye ${ }^{\circledR}$ Terminator v3.1 Cycle Sequencing Kit (Life Technologies - Applied Biosystems) and the equipment used was ABI 3730 DNA Analyzer (Life Technologies Applied Biosystems). We edited the obtained sequences using the software BIOEDIT (Hall, 1999) and MUSCLE 3.6 (Edgar, 2004) and compared with the GenBank databases (https://www.ncbi.nlm.nih.gov/genbank/) and BOLDSYSTEM (http://www.boldsystems.org/).

\section{Data analysis}

The number of nests for each species and area was compared using Mann-Whitney test with a significance level of 5\% (BioEstat 5.0 program; Ayres and Ayres Junior, 2000). The identification of specific mtDNA - COI haplotypes, as well as haplotypic (h) and nucleotide $(\pi)$ diversity were performed using the DnaSP 4.9 software (Rozas et al., 2003). The haplotype network was created using the Network 4.5 software (fluxus-enginnering.com), using the parameter Median-Joining (Bandelt et al., 1999).

We aligned the sequences obtained with ClustalW (Higgins et al., 1992) from the BioEdit software (Hall, 1999). Next, we used the Model Finder software (Kalyaanamoorthy et al., 2017) to choose the best molecular evolution model 
according to AICc for each species, being TPM2u $+\mathrm{F}+$ G4 and TPM $2 \mathrm{u}+\mathrm{F}+\mathrm{I}$ the best model for S. saevissima and $S$. invicta, respectively. Subsequently, we inferred the phylogenetic tree through the Maximum likelihood method with 1000 bootstrap replicates for each species in the online IQ tree software (Nguyen et al., 2015; Trifinopoulos et al., 2016), using the sequence of $S$. interrupta (Cod. Genbank AY950727) as an outgroup. The Ape and Phytools packages (Paradis et al., 2004; Maintainer and Revell, 2020) of software $\mathrm{R}$ (R Core Team, 2021) were used to reconstruct ancestral character states (Reconstruction of Ancestral State - SRA) from the original habitat of these Solenopsis species for the region. To this end, we assigned each habitat of origin (urban or rural) to each tip of our topologies. The 'equal rates' (ER) model and the 'all different rates' (ARD) model were compared with the likelihood ratio test (LRT) (Pagel, 1994; Schluter et al., 1997) to determine which model best fits for our date. The probability distribution of the states was calculated running 10000 generations of MCMC, sampling every 100 generations (Huelsenbeck et al., 2003). Through SIMMAP function (Bollback, 2006) we generated 100 maps of stochastic characters from our data set, which were summarized considering the number of changes, the proportion of time spent in each urban or rural state and the latest probabilities that each internal node is in each state, under the best model.

\section{Results}

The morphological identification shows us that workers of $S$. saevissima have the head subquadrate to weakly ovate, lack of median frontal streak, complete mandibular costulae, mesonotum is weakly convex in lateral view, and post-petiole in posterior view is higher than wide, with transversely rugose sculpture only in the lower portion and surface in the upper portion is smooth shiny (Figure S1). In the workers of $S$. invicta, we observed the head subquadrate to weakly cordate, presence of the median frontal streak, mandibular costulae absent medially, mesonotum convex in lateral view, post-petiole is wider than high in posterior view with sculpture transversely rugose to punctate-rugose covering most of the view (Figure S2). Solenopsis saevissima can be distinguished from $S$. invicta, and both from the others fire ant's species, by these diagnostics characters, as described by Pitts et al. (2018).

Molecular sequencing confirmed the results of the morphological identification. The mtDNA sequences of the collected specimens were compared with those deposited in the GenBank database. Thus, our study found 103 nests of S. saevissima and 83 nests of S. invicta (Figure 1; Table S1). Our sequences showed $98 \%$ to $100 \%$ similarities with other Solenopsis spp. already identified in the database. All details of the identifications with the respective access codes were summarized in Table S1. Regarding the haplotype diversity recovered in the present study, S. saevissima has the greatest haplotype diversity compared to $S$. invicta (Table 1 ).

The network analysis facilitates the visualization of the two distinct species and their haplotypes explored in this study at different habitats (Figure 2). Solenopsis saevissima has a higher number of haplotypes associated with the rural habitat, while $S$. invicta has the same occurrence of haplotypes in both rural and urban habitat. In addition, our data identified 15 haplotypes of $S$. saevissima in total. The majority of these haplotypes were found exclusively in the urban or rural habitat. However, there were also the presence of some haplotypes occurring in both urban and rural habitat, i.e., H_4, H_16, H_7 and $\mathrm{H} \_8$ (Figure 2). For S. invicta we recovered nine distinct haplotypes, three of which occurred in both urban and rural habitat (H_11, H_12 and H_13). The remaining haplotypes were found to be exclusive to a particular habitat, as can be



Figure 1 - Geographic location of the counties and collection sites of Solenopsis nests. Circle: S. saevissima $(\mathrm{n}=103)$; triangle: S. invicta nests ( $\mathrm{n}=83)$. 
Table 1 - Number of haplotypes and haplotype diversity found in each species analyzed.

\begin{tabular}{lcc}
\hline & $\begin{array}{c}\text { Solenopsis saevissima } \\
(\mathrm{n}=103 \text { nests })\end{array}$ & $\begin{array}{c}\text { Solenopsis invicta } \\
(\mathrm{n}=83 \text { nests })\end{array}$ \\
\hline Rural & Number haplotypes & Number haplotypes \\
Urban & 13 & 6 \\
\hline & 6 & 6 \\
\hline Rural & Haplotype diversity & Haplotype diversity \\
Urban & 0.7998 & 0.8367 \\
General & 0.6185 & 0.3521 \\
& 0.9105 & 0.6985 \\
\hline \multicolumn{2}{c}{} \\
\hline
\end{tabular}



Figure 2 - Network of haplotypes of Solenopsis saevissima and Solenopsis invicta. The habitat of the sample was highlighted with the colors green and orange corresponding to the rural and urban habitats, respectively. Dotted circles indicate the delimitation of each species. The red point was added by the program as hypothetical haplotype.

seen in Figure 2. Still on the network analysis, despite the fact that H_12 is classified as $S$. invicta and was found as in urban and rural habitat, it still presented quite distinct of the other S. invicta haplotypes recovered in the present study. This $\mathrm{H}_{-} 12$ haplotype has already been identified in previous studies in S. invicta in Mississippi, USA (access code EU352608), as well as in Argentina (access code JN808817). More studies targeting different genes may contribute more to understanding the evolutionary history of Solenopsis, in particular about this H_12 haplotype.

We then analyzed whether $S$. invicta and $S$. saevissima occur at different frequencies in urban and rural habitats.
In the rural area $S$. invicta was registered less occurrence of nests $(U=89.50 ; Z(u)=3.29 ; p=0.0005$; Figure $3 A)$, when compared to $S$. saevissima. In the urban area, these species have the same occurrence of nests $(U=167.00 ; Z(u)=1.3458$; $\mathrm{p}=0.1784$; Figure 3B).

In order to proceed with the ancestral state reconstruction analyses, we first tested the best evolutionary model for our data. Therefore, likelihood ratio testing (LRT) showed that the best model that fits our data was the ARD (all rates different). This ARD model considers that the rate transitions in each state (rural or urban) are different, compared to the ER model (equal rates) (see Table S2). 
A

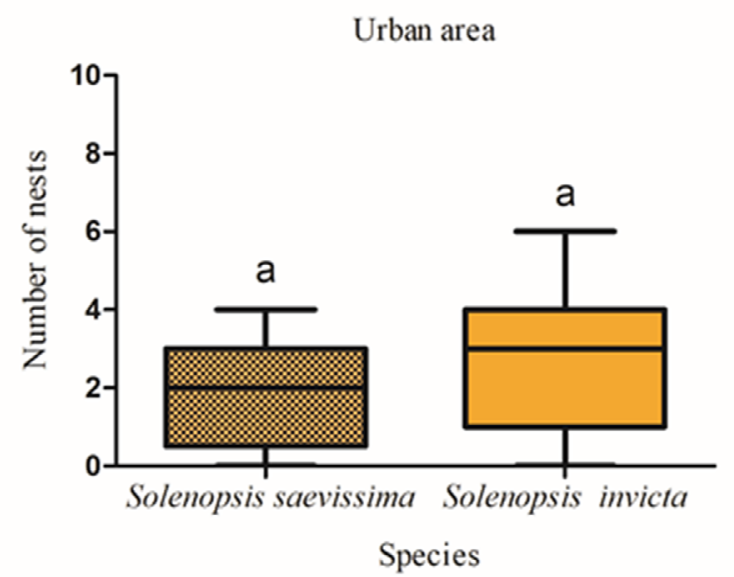

B

Figure 3 - Comparison of the number of nests in urban (A) and rural (B) populations of Solenopsis saevissima and Solenopsis invicta. The lines inside each bar represent the median. Different letters represent statistically significant differences (Mann-Whitney test, $\mathrm{p}<0.05$ ).

Once chosen the best evolutionary model, we then tested the probability of the habitat of origin of each species with ancestral state reconstruction (ASR) analysis. Our ASR results shows that the ancestor of $S$. saevissima for the studied region has a $90 \%$ probability of having a rural origin (90\% rural and 10\% urban), while S. invicta 53\% rural and $47 \%$ urban. The red arrows in Figure 4 highlight these ancestral state probabilities for each species (see Figures $\mathrm{S} 3$ and S4 for the entire names of the tips). In addition, for $S$. saevissima and $S$. invicta there were multiple transitions from rural to urban environment with a special emphasis on a lineage of $S$. saevissima that once acquired the status of urban, remained urban practically throughout the clade, with only a few exceptions. This shows that there may be a specialization of this lineage of $S$. saevissima for urban habitat, despite the great majority of the recovered diversity being associated with the rural environment (Figure 4). The analysis of ancestral state reconstruction (ASR) for the habitat of $S$. invicta for the region shows under the lens of phylogeny that in addition to having multiple transitions between rural and urban environments, there is no specialization of lineage for these habitats. However, S. invicta is overall more associated with the urban environment (Figure 4).

\section{Discussion}

In this study we analyzed the occurrence of two species of fire ants (S. saevissima and $S$. invicta) in urban and rural habitats next to fragments of the Atlantic Forest (Neotropical region) (see Figure 1 and Table S1). The present study evaluated the frequency of occurrence, haplotype diversity and also brought insights about the habitat of origin of each fire ant species for this region. We used morphological characters suggested by Pitts et al. (2018) and DNA Barcode technique for species diagnosis, because Solenopsis species identification is complex due to the high degree of polymorphism of workers (Pitts et al., 2005, 2018), and presence of hybridization (Stolle et al., 2021). Our results suggest that the use of both methods is crucial for the identification of $S$. saevissima and $S$. invicta.

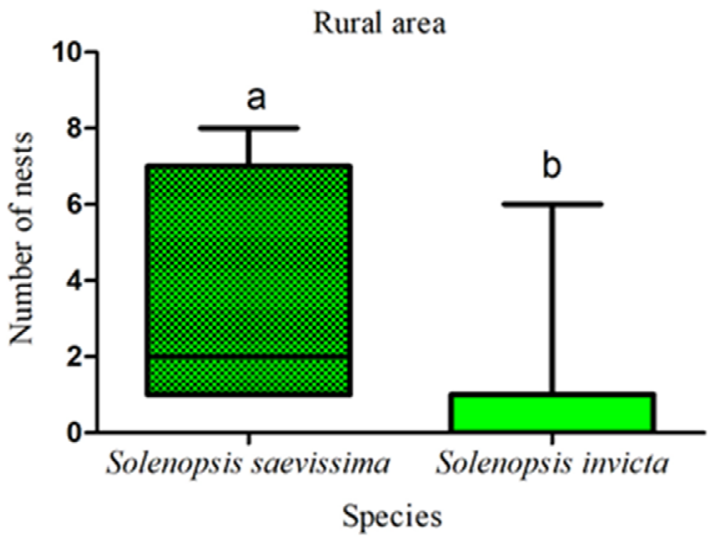

Our results show that $S$. saevissima and S. invicta are present in both areas, however, we show that the frequency of occurrence is not the same. The non-dominance of S. invicta is likely related to the characteristics of urbanization [e.g., the presence of more native vegetation and grass on the soil surface (see Kafle et al., 2009) or to abiotic factors, e.g., temperature and rainfall (Korzukhin et al., 2001; Morrison et al., 2004; Byeon et al., 2020; Chen et al., 2020), which should be more favorable to $S$. saevissima. Additionally, we suggest that in urban areas, the populations of $S$. saevissima must be reduced due to the competitive, strong adaptive and reproductive capacity of S. invicta to explore resources and colonize diverse habitats (Fowler, Bernardi and di Romagnano, 1990; Ross and Shoemaker, 2008; LeBrun, Plowes and Gilbert, 2012). The fire ant social organization could also indicate the success of the species, as polygynous colonies have a high number of individuals and queens has a lower dispersal capacity when compared to monogynous colonies (Macom and Porter, 1996; Deheer et al., 1999; Stolle et al., 2021). However, in previous studies we investigated this component by sequencing the GP-9 gene with samples from the same nests in the present study. Our results confirmed that all colonies of the two species were monogynous (see Alves et al., 2018; Souza, 2019).

In this study, we observed populations of $S$. saevissima with darker specimens, which is a variant registered in Brazil between Goiás and Bahia, including São Paulo State (Pitts et al., 2018). Solenopsis invicta is characteristic of the northern region of Porto Velho (Rondônia State, Brazil) and Cuiabá (Mato Grosso State, Brazil) (Pitts et al., 2018), and in neighboring countries like Argentina, Bolivia, Paraguay, and Uruguay (Pitts, McHugh and Ross, 2005; Ross et al., 2007). In the state of São Paulo (southeastern Brazil) the species is associated with the Cerrado patches (Fowler et al., 1990), with expansion of territory to areas under Atlantic Forest dominance (Martins et al., 2014; Souza et al., 2014). In addition to agriculture (Pacheco et al., 2013, 2017), urban growth contributes greatly to the expansion of the foraging territory of the populations of S. invicta, increasing its range of distribution (Plowes et al., 2007). 


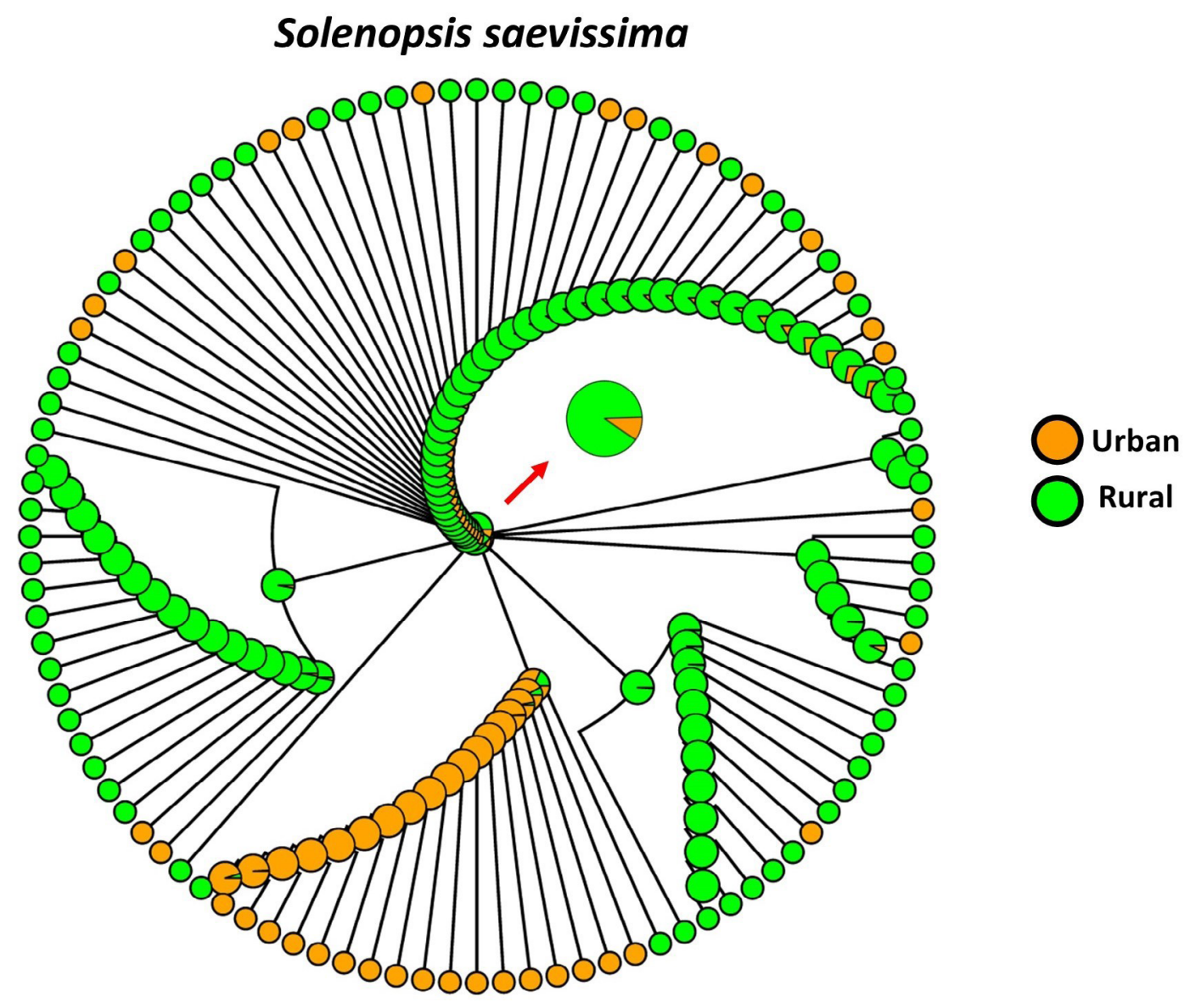

Solenopsis invicta

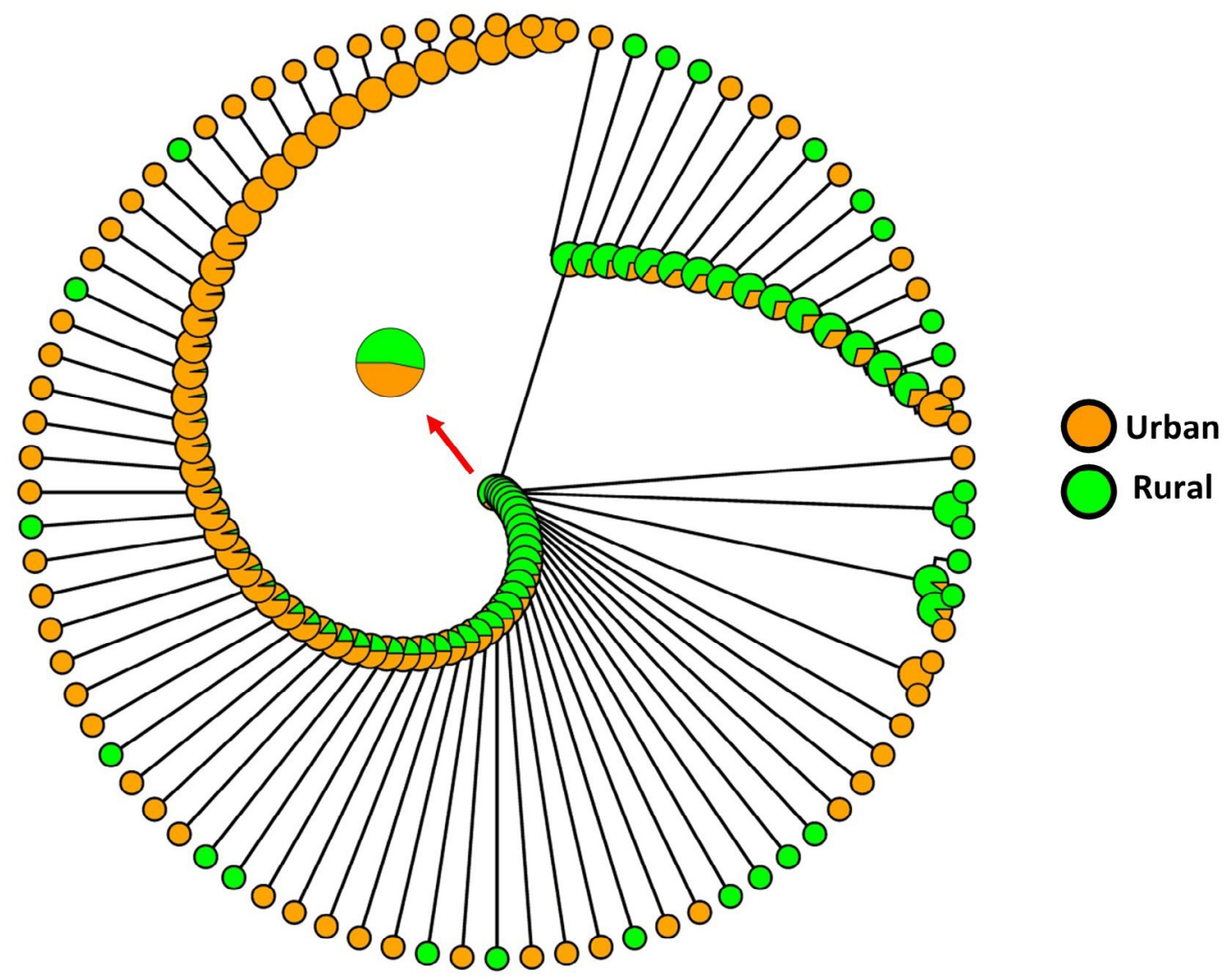

Figure 4 - Summary of all stochastic character maps for ancestral state reconstruction of the habitat of Solenopsis saevissima and Solenopsis invicta for the studied region. Red arrows highlight the probability of the state of the ancestor of each species. Model = all rates different (ARD). 
Our study areas include a region with accelerated urban growth (Lima and Magaña Rueda, 2018) and, at the same time, many conserved remnants of the Atlantic (Torres et al., 2019). Solenopsis invicta does not affect native ant communities in more preserved forest remnants, suggesting that their competitive dominance occurs largely in disturbed habitats (King and Porter, 2007).

When native habitats are disturbed and/or fragmented, the introduction and establishment of invasive species is facilitated (Sakai et al., 2001; Holway et al., 2002). As the native vegetation of the Atlantic Forest has been strongly fragmented (Marques, 2020), the environment is favorable for $S$. invicta to expand its territory. Analyses of genetic diversity of populations of S. invicta (Souza, 2019) show that the species is undergoing an expansion process in the same region of our study.

In places where native vegetation is dominant in the landscape, as is the case in rural areas (e.g., in the vicinity of agricultural properties and dirt roads), S. saevissima was the most abundant species. In addition, our results on haplotypic diversity show that $S$. saevissima is the more diverse, suggesting that it is the species native to the region, as had been discussed by Pitts et al. (2005). Also, high haplotype diversity values of this species corroborate data from Ross $e t$ al. (2010). This evidence corroborates with the observed of S. saevissima being more likely to be found in rural sampling sites and coming from an older population.

In contrast, $S$. invicta recovered in this study showed lower genetic diversity, which is consistent with previous studies (Ahrens et al., 2005). Additionally, one haplotype appears to be the most frequent and dominant in the region (H_13), with several additional haplotypes having recent ancestry from the main haplotype. These data suggest that $S$. invicta is expanding to the region, but with a pattern consistent with a bottleneck introduction and its subsequent spread. A similar pattern was observed for S. invicta populations in Taiwan, and USA where studies also found evidence of recent introduction associated with molecular signatures of genetic bottlenecks (Shoemaker et al., 2006; Yang et al., 2008,).

In addition, our reconstruction of the ancestral state results shows that $S$. saevissima is very likely to have a rural ancestor, which is expected since it is native to the region. And even with all the associated diversity, S. saevissima in general continues to present a greater probability of being associated with rural habitat (Lunz et al., 2009; Martin et al., 2011), except for a lineage that evolved for urban. In contrast, $S$. invicta presented a probability of $53 \%$ rural and $47 \%$ urban of its habitat ancestral state. However, although one lineage specialized in rural first, another lineage specialized in urban, and this seems to be the most common. These data explain in light of the evolutionary process of ancestry why $S$. saevissima seems to be more propitiate to rural habitat and $S$. invicta seems to be more successful in an urban environment, thus corroborating several other studies prior to this one (Tsutsui and Suarez, 2003; Gusmão et al., 2010; Wetterer and Davis, 2010). Although our data advance the knowledge about the diversity and origin of these species for the region, we need to recognize that the present study only considered the mitochondrial lineage. Therefore, future studies should incorporate other genetic markers, especially nuclear genes.

\section{Conclusions}

Our results show that the most common species of fire ants in Brazil are not found in equal amounts in urban and rural habitats. We show that $S$. saevissima is more characteristic of rural environments with greater haplotypic diversity. In the urban environment, $S$. invicta is not characterized as the dominant species, dividing the foraging territory with $S$. saevissima. Our work is the first to investigate the ancestral state of urban and rural habitats of both $S$. saevissima and $S$. invicta species in the Atlantic Forest Dominion region in the evolutionary context. Thus, the present work adds important information that serves as a subsidy for the protection of S. saevissima, which is the species native to the region, according to our results. The maintenance of vegetation in urban areas can be a good mechanism to prevent the advancement of $S$. invicta in the region. As the study areas belong to the Brazilian Atlantic Domain, our results, in a more comprehensive way, can help public policy programs aimed at the conservation of this biome.

\section{Acknowledgements}

The authors wish to thank the Universidade de Mogi das Cruzes for support regarding the use of its infrastructure. This work was supported by the São Paulo Research Foundation (FAPESP) (Protocol No. 2015/05126-8, coordinated by MSCM), the National Council for Scientific and Technological Development (CNPq) for support to LM and RFS, and the Education and Research Support Foundation (FAEP) for their financial support.

\section{Conflict of Interest}

The authors declare no competing interests.

\section{Author Contributions}

MOR was responsible for the original draft, analyzed the data, writing-review and editing; LM conducted the experiments; RFS conducted field collections and experiments; DYK conducted the experiments; JMCA conducted the experiments and analyzed the data; $\mathrm{RH}$ analyzed the data; VHN conducted field collections and morphological identification of ants; OGMS conducted field collections and morphological identification of ants; OCB writing-review and editing; MSCM was responsible for conceptualization, writing - original draft, writing - review and editing; all authors read and approved the final version.

\section{References}

Ahrens ME, Ross KG and Shoemaker DD (2005) Phylogeographic structure of the fire ant Solenopsis invicta in its native South American range: Roles of the natural barriers and habitat connectivity. Evolution 59:1733-1743.

Alves JMC, Souza RF and Morini MSC (2018) Ocorrência e condição social de espécies de Solenopsis spp. em fragmentos de Mata Atlântica. Rev Cientif UMC 3:1-4.

Ayres M and Ayres Junior M (2000) BioEstat 2.0: Aplicações estatísticas nas áreas das ciências biológicas e médicas. Sociedade Civil Mamirauá, Belém, 259 p. 
Bandelt HJ, Forster P and Röhl A(1999) Median-joining networks for inferring intraspecific phylogenies. Mol Biol Evol 16:37-48.

Banks WA, Adams CT, Lofgren CS and Wojcik DP (1990) Imported fire ant infestation of soybean fields in the southern United States. Fla Entomol 73:503-504.

Bertelsmeier C, Luque GM, Hoffmann BD and Courchamp F (2015) Worldwide ant invasions under climate change. Biodivers Conserv 24:117-128.

Bollback JP (2006) SIMMAP: Stochastic character mapping of discrete traits on phylogenies. BMC Bioinformatics 7:88.

Bueno OC (2017) Criação de formigas em laboratório. In: Bueno OC and Campos AEC (eds) Formigas em ambientes urbanos no Brasil. Editora Canal6, Bauru, pp 125-142.

Byeon DH, Lee JH, Lee HS, Park Y, Jung S and Lee WH (2020) Prediction of spatiotemporal invasive risk by the red imported fire ant (Hymenoptera: Formicidae) in South Korea. Agronomy (Basel) 10:875.

Chan KH and Guénard B (2020). Ecological and socio-economic impacts of the red import fire ant, Solenopsis invicta (Hymenoptera: Formicidae), on urban agricultural ecosystems. Urban Ecosystems 23:1-12.

Chen S, Ding F, Hao M and Jiang D (2020) Mapping the potential global distribution of red imported fire ant (Solenopsis invicta Buren) based on a machine learning method. Sustainability (Basel) 12:10182.

Colombo AF and Joly CA (2010) Brazilian Atlantic Forest lato sensu: The most ancient Brazilian forest, and a biodiversity hotspot, is highly threatened by climate change. Braz J Biol 70:697-708.

Crist TO (2009) Biodiversity, species interactions, and functional roles of ants (Hymenoptera: Formicidae) in fragmented landscapes: A review. Myrmecol News 12:3-13.

DeHeer CJ, Goodisman MA and Ross KG (1999) Queen dispersal strategies in the multiple-queen form of the fire ant Solenopsis invicta. An Nat 153:660-675.

Dejean A, Céréghino R, Leponce M, Rossi V, Roux O, Compin A, Delabie JHC and Corbara B (2015) The fire ant Solenopsis saevissima and habitat disturbance alter ant communities. Biol Conserv 187:145-153.

Edgar RC (2004) MUSCLE: Multiple sequence alignment with high accuracy and high throughput. Nucleic Acids Res 32:17921797.

Fernandes EF, Santos-Prezoto HH and Prezoto F (2016) Formigas lava-pés em ambientes urbanos: Bioecologia e riscos de acidentes. CES Revista 30:25-42.

Fiaschi P and Pirani JR (2009) Review of plant biogeographic studies in Brazil. J Syst Evol 47:477-496.

Fowler HG, Bernardi JVE and di Romagnano LF (1990) Community Structure and Solenopsis invicta in Sao Paulo. In: Vander Meer RK, Jaffé K and Cedeno A (eds). Applied Myrmecology: A World Perspective. Taylor \& Francis Group, London, pp 199-207.

Fox EGP, Pianaro A, Solis DR, Delabie JHC, Vairo BC, Machado EDA and Bueno OC (2012) Intraspecific and intracolonial variation in the profile of venom alkaloids and cuticular hydrocarbons of the fire ant Solenopsis saevissima Smith (Hymenoptera: Formicidae). Psyche J Entomol 2012:398061.

Gusmão FA, Harakava R and Campos AEC (2010) Fire-ants of the Solenopsis saevissima species-group (Hymenoptera: Formicidae) nesting in parks in the city of São Paulo: Identification based on mtDNA. Sociobiology 56:353-362.

Haddad Junior V and Larsson CE (2015) Anaphylaxis caused by stings from the Solenopsis invicta, lava-pés ant or red imported fire ant, An Bras Dermatol 90:S22-S25.

Hall T (1999) BioEdit: A user-friendly biological sequence alignment editor and analysis program for Windows 95/98/NT. Nucleic Acids Symp Ser 41:95-98.
Hebert PDN, Ratnasingham S and DeWaard JR (2003) Barcoding animal life: Cytochrome c oxidase subunit 1 divergences among closely related species. Proc Biol Sci 270:S96-99.

Higgins D, Bleasby A and Fuchs R (1992) CLUSTAL V: Improved software for multiple sequence alignment. Comput Appl Biosci 8:189-191.

Holway DA, Lach L, Suarez AV, Tsutsui ND and Case TJ (2002) The causes and consequences of ant invasions. Annu Rev Ecol Syst 33:181-233.

Huelsenbeck JP, Nielsen R and Bollback JP (2003) Stochastic mapping of morphological characters. Syst Biol 52:131-158.

Joly CA, Metzger JP and Tabarelli M (2014) Experiences from the Brazilian Atlantic Forest: Ecological findings and conservation initiatives. New Phytol 204:459-473.

Kafle L, Wu WJ, Vander Meer RK and Shih CJ (2009) Effect of surfaces on the foraging efficiency of Solenopsis invicta (Hymenoptera: Formicidae). Formos Entomol 29:51-58.

Kalyaanamoorthy S, Minh BQ, Wong TK, Von Haeseler A and Jermiin LS (2017) ModelFinder: Fast model selection for accurate phylogenetic estimates. Nat Methods 14:587-589.

King JR and Porter SD (2007) Body size, colony size, abundance, and ecological impact of exotic ants in Florida's upland ecosystems. Evol Ecol Res 9:757-774.

King JR and Tschinkel WR (2008) Experimental evidence that human impacts drive fire ant invasions and ecological change. Proc Natl Acad Sci U S A 105:20339-20343.

Korzukhin MD, Porter SD, Thompson LC and Wiley S (2001) Modeling temperature-dependent range limits for the fire ant Solenopsis invicta (Hymenoptera: Formicidae) in the United States. Environ Entomol 30:645-655.

Lai LC, Hua KH and Wu WJ (2015) Intraspecific and interspecific aggressive interactions between two species of fire ants, Solenopsis geminata and S. invicta (Hymenoptera: Formicidae) in Taiwan. J Asia-Pac Entomol 18:93-98.

LeBrun EG, Plowes RM and Gilbert LE (2012) Imported fire ants near the edge of their range: Disturbance and moisture determine prevalence and impact of an invasive social insect. J Anim Ecol 81: 884-895.

Lima GN and Magaña Rueda VO (2018) The urban growth of the metropolitan area of Sao Paulo and its impact on the climate. Weather Clim Extrem 21:17-26.

Lunz AM, Harada AY, Aguiar TDS and Cardoso AS (2009) Danos de Solenopsis saevissima F Smith (Hymenoptera: Formicidae) em Paricá Schizolobium amazonicum. Neotrop Entomol 38:285-288.

Macom TE and Porter SD (1996) Comparison of polygyne and monogyne red imported fire ants (Hymenoptera: Formicidae) population densities. Ann Entomol Soc Am 89:535-543.

Marques M (2020) The Atlantic Forest: History, biodiversity, threats and opportunities of the mega-diverse forest. Springer Nature, Berlin, $517 \mathrm{p}$.

Martin JM, Roux O, Groc S and Dejean A (2011) A type of unicoloniality within the native range of the fire ant Solenopsis saevissima. C R Biol 334:307-310.

Martins C, de Souza RF and Bueno OC (2014) Molecular characterization of fire ants, Solenopsis spp., from Brazil based on analysis of mtDNA gene cytochrome oxidase. J Insect Sci 14:50.

Morrison LW, Porter SD, Daniels E and Korzukhin MD (2004) Potential global range expansion of the invasive fire ant, Solenopsis invicta. Biol Invasions 6:183-191.

Nguyen LT, Schmidt HA, Von Haeseler A and Minh BQ (2015) IQTREE: A fast and effective stochastic algorithm for estimating maximum-likelihood phylogenies. Mol Biol Evol 32:268-274. 
Orivel J and Dejean A (2002) Ant activity rhythms in a pioneer vegetal formation of French Guiana (Hymenoptera: Formicidae). Sociobiology 30:65-76.

Pacheco R and Vasconcelos HL (2007) Invertebrate conservation in urban areas: Ants in the Brazilian Cerrado. Landscape Urban Plan 81:193-199.

Pacheco R, Camacho GP, Frizzo TL and Vasconcelos HL (2017) Effects of land-use changes on ecosystem services: Decrease in ant predation in human-dominated landscapes in central Brazil. Entomol Exp Appl 162:302-308.

Pacheco R, Vasconcelos HL, Groc S, Camacho GP and Frizzo TL (2013) The importance of remnants of natural vegetation for maintaining ant diversity in Brazilian agricultural landscapes. Biodivers Conserv 22:983-997.

Pagel M (1994) Detecting correlated evolution on phylogenies: A general method for the comparative analysis of discrete characters. Proc Soc Lond B Biol Sci 255:37-45.

Paradis E, Claude J and Strimmer K (2004) APE: Analyses of phylogenetics and evolution in $\mathrm{R}$ language. Bioinformatics 20:289-290.

Penick CA and Tschinkel WR (2008) Thermoregulatory brood transport in the fire ant, Solenopsis invicta. Insect Soc 55:176182.

Pitts JP, Camacho GP, Gotzek D, Mchugh JV and Ross KG (2018) Revision of the fire ants of the Solenopsis saevissima speciesgroup (Hymenoptera: Formicidae). Proc Entomol Soc Wash 120:308-411.

Pitts JP, McHugh JV and Ross KG (2005) Cladistic analysis of the fire ants of the Solenopsis saevissima species-group (Hymenoptera: Formicidae). Zool Scr 34:493-505.

Plowes RM, Dunn JG and Gilbert LE (2007) The urban fire ant paradox: Native fire ants persist in an urban refuge while invasive fire ants dominate natural habitats. Biol Invasions 9:825-836.

Porter SD and Tschinkel WR (1987) Foraging in Solenopsis invicta (Hymenoptera: Formicidae): Effects of weather and season. Environ Entomol 16:802-808.

Rabello AM, Parr CL, Queiroz AC, Braga DL, Santiago GS and Ribas CR (2018) Habitat attribute similarities reduce impacts of land-use conversion on seed removal. Biotropica 50:39-49.

Ratnasingham S and Hebert PDN (2007) bold: The Barcode of Life Data System (http://www.barcodinglife.org). Mol Ecol Notes 7:355-364.

Ribeiro MC, Metzger JP, Martensen AC, Ponzoni FJ and Hirota MM (2009) The Brazilian Atlantic Forest: How much is left, and how is the remaining forest distributed? Implications for conservation. Biol Conserv 142:1141-1153.

Ross KG and Shoemaker DDW (2008) Estimation of the number of founders of an invasive pest insect population: The fire ant Solenopsis invicta in the USA. Proc Biol Sci 275:2231-2240.

Ross KG, Gotzek D, Ascunce MS and Shoemaker DD (2010) Species delimitation: A case study in a problematic ant taxon. Syst Biol 59:162-184.

Ross KG, Krieger MJ, Keller L and Shoemaker DD (2007) Genetic variation and structure in native populations of the fire ant Solenopsis invicta: Evolutionary and demographic implications. Biol J Linn Soc 92:541-560.

Roux O, Rossi V, Céréghino R, Compin A, Martin JM and Dejean A (2013) How to coexist with fire ants: The roles of behaviour and cuticular compounds. Behav Processes 98:51-57.

Rozas J, Sánchez-DelBarrio JC, Messeguer X and Rozas R (2003) DnaSP, DNA polymorphism analyses by the coalescent and other methods. Bioinformatics 19:2496-2497.
Sakai AK, Allendorf FW, Holt JS, Lodge DM, Molofsky J, With KA, Baughman S, Cabin RJ, Cohen JE, Ellstrand NC et al. (2001) The population biology of invasive species. Annu Rev Ecol Syst 32:305-332.

Sartorello R (2018) A Serra do Itapeti: Caminhos das pedras e caminhos das águas. In: Morini MSC, Oliveira CRdS, Wuo M, de Almeida-Scabbia RJ and Sartorello R (eds) Zona de Amortecimento do Parque Natural Municipal Francisco Affonso de Mello. Editora Canal6, Bauru, pp 19-29.

Schluter D, Price T, Mooers AØ and Ludwig D (1997) Likelihood of ancestor states in adaptive radiation. Evolution 51:1699-1711.

Schoereder JH, Guerra Sobrinho T, Ribas CR and Campos RB (2004) Colonization and extinction of ant communities in a fragmented landscape. Austral Ecol 29:391-398.

Shoemaker DD, Deheer CJ, Krieger MJ and Ross KG (2006) Population genetics of the invasive fire ant Solenopsis invicta (Hymenoptera: Formicidae) in the United States. Ann Entomol Soc Am 99:1213-1233.

Souza RF (2019) Aspectos bioecológicos e genéticos de Solenopsis spp. no mosaico de paisagens do Alto Tietê Cabeceiras (sp). B. Sc. Thesis, Universidade de Mogi das Cruzes, Mogi das Cruzes, $138 \mathrm{p}$.

Souza RFd, Martins C, Pereira RM and Bueno OC (2014) Analysis of the hypervariable regions (HVRs) of the wsp gene of Wolbachia from Solenopsis invicta ants in Southeastern Brazil. Adv Entomol 02:135-143.

Stolle E, Pracana R, Priebe MK, Hernández GL, Castillo-Carrillo C, Arias MC, Paris CI, Bollazzi M, Priyam A, LópezOsorio F et al. (2021) Recurring adaptive introgression of a supergene that determines social organization. bioRxiv. DOI: 10.1101/2021.04.11.439370.

Tabarelli M, Pinto LP, Silva JMC, Hirota MM and Bedê LC (2005) Desafios e oportunidades para a conservação da biodiversidade na Mata Atlântica brasileira. Megadiversidade 1:132-138.

Torres PHC, Ramos RF and Gonçalves LR (2019) Environmental conflicts at São Paulo macrometropolis: Paranapiacaba and São Sebastião. Ambient Soc 22:101.

Trager JC (1991) A revision of the fire ants, Solenopsis geminata group (Hymenoptera: Formicidae: Myrmicinae). J New York Entomol S 99:141-198.

Trifinopoulos J, Nguyen LT, von Haeseler A and Minh BQ (2016) W-IQ-TREE: A fast online phylogenetic tool for maximum likelihood analysis. Nucleic Acids Res 44:W232-W235.

Tschinkel WR (2006) The fire ants. Belknap Press of Harvard University Press, London, $752 \mathrm{p}$.

Tsutsui ND and Suarez AV (2003) The colony structure and population biology of invasive ants. Conserv Biol 17:48-58.

Ulloa-Chacon P (2003) Hormigas urbanas. In: Fernandez F (ed.) Introducción a las Hormigas de la Región Neotropical. Instituto de Investigación de Recursos Biológicos Alexander von Humboldt, Bogotá, pp. 351-359.

Wang L, Xu YJ, Zeng L and Lu YY (2019) Impact of the red imported fire ant Solenopsis invicta Buren on biodiversity in South China: A review. J Integr Agric 18:788-796.

Wetterer JK and Davis LR (2010) Solenopsis invicta (Hymenoptera: Formicidae) in the Lesser Antilles. Fla Entomol 93:128-129.

Wilder SM, Barnum TR, Holway DA, Suarez AV and Eubanks MD (2013) Introduced fire ants can exclude native ants from critical mutualist-provided resources. Oecologia 172:197-205.

Yang CC, Shoemaker DD, Wu WJ and Shih CJ (2008) Population genetic structure of the red imported fire ant, Solenopsis invicta, in Taiwan. Insectes Soc 55:54-65. 
Zeringóta V, De Castro MM, Della Lucia TMC and Prezoto F (2014) Nesting of the fire ant Solenopsis saevissima (Hymenoptera: Formicidae) in an urban environment. Fla Entomol 97:668-673.

\section{Internet Resources}

AntWeb - AntWeb.org (2021), https://www.antweb.org/ (accessed 1 April 2021)

Bolton B (2021) An online catalog of the ants of the world, AntCat, http://www.antcat.org/ (accessed 20 October 2016).

IBGE - Portal do IBGE (2020), https://ibge.gov.br/ (accessed 1 April 2021)

Maintainer LJR and Revell LJ. Package phytools title phylogenetic tools for comparative biology (and Other Things), http:// nbcgib.uesc.br/mirrors/cran/web/packages/phytools/phytools. pdf (accessed 28 April 2020).

R Core Team (2021) R: A language and environment for statistical computing. R Foundation for Statistical Computing, Vienna, Austria, http://www.r-project.org/ (accessed 21 September 2020).

\section{Supplementary material}

The following online material is available for this article:

Table S1 - Samples of Solenopsis saevissima and Solenopsis invicta collected in the present study.
Table S2 - Likelihood ratio test (LRT) of the ER ('equal rates') and ARD ('all different rates') models to select the optimal model for ancestral state reconstruction.

Figure S1 - Scanning electron microscopy images of Solenopsis saevissima.

Figure S2 - Scanning electron microscopy images and frontal photograph of Solenopsis invicta.

Figure S3 - Analysis ancestral state reconstruction (ASR) for Solenopsis saevissima with the ARD model with the names of the tips.

Figure S4 - Analysis ancestral state reconstruction (ASR) for Solenopsis invicta with the ARD model with the names of the tips.

License information: This is an open-access article distributed under the terms of the Creative Commons Attribution License (type CC-BY), which permits unrestricted use, istribution and reproduction in any medium, provided the original article is properly cited. 